\title{
Analysis on the Manufacturing of an AA5083 Straight Blade Previously ECAE Processed
}

\author{
Daniel Salcedo, Carmelo Luis, Ignacio Puertas, Javier León, \\ Juan Pablo Fuertes, and Rodrigo Luri
}

Mechanical, Energetics and Materials Engineering Department, Public University of Navarre, Campus de Arrosadia s/n, 31006 Pamplona, Spain

Correspondence should be addressed to Carmelo Luis; cluis.perez@unavarra.es

Received 29 May 2013; Accepted 22 September 2013

Academic Editor: Min Wang

Copyright (C) 2013 Daniel Salcedo et al. This is an open access article distributed under the Creative Commons Attribution License, which permits unrestricted use, distribution, and reproduction in any medium, provided the original work is properly cited.

Over these past few years, there have been a large number of technical papers published related to the problem of improving the mechanical properties of materials obtained through severe plastic deformation. Nevertheless, the number of technical papers dealing with improvement in the mechanical properties of mechanical components manufactured from submicrometric grain size material has not been so proficient. Therefore, in this present research work, a straight blade has been manufactured starting from AA-5083 previously processed by ECAE twice (N2) with route C. This material will be manipulated so as to be isothermally forged at different temperature values. This present research work shows the results that are inherent in an improvement in the mechanical properties and the microstructure achieved in the thus obtained components, compared with the starting material. In addition, the optimum forging temperature to achieve these components will be determined. As shown in this research work, it is possible to obtain submicrometric grain size mechanical components with a higher mechanical strength than those obtained in nonultrafine grained materials. The originality of this research work lies in the manufacturing of actual mechanical components from ECAE processed material and the analysis of their properties.

\section{Introduction}

This research work presents a study on the forgeability of a straight blade made from an aluminium alloy AA-5083. The main aim of this present paper is to demonstrate that the use of ECAE processed AA-5083 as starting material makes it possible to forge a part, in this case in the shape of a straight blade, improving its mechanical properties, if it is compared with the use of annealed AA-5083 as initial material. Although some other severe plastic deformation (SPD) processes exist such as the accumulative torsion back (ATB) process [1], multi-axial compressions/forging (MAC/F) [2], and the accumulative roll bonding (ARB) process [3], the process employed here to obtain submicrometric grain size starting material was equal channel angular extrusion (ECAE) [4], which is the most popular SPD process, and it consists in the extrusion of the material through a die with two channels of the same cross section that intersect at an angle [5]. Generally, this intersection angle varies between $90^{\circ}$ and $135^{\circ}$, and the material to be processed is deformed by a mechanism of shear strain.

With regard to the ECAE process, one could highlight those about the ECAE of aluminium alloys [6-8]. In research work by Fu et al. [6] three die design cases are studied through finite element simulation. An aluminium alloy 6061 is used, and the ECAE process is carried out at room temperature. Based on their study, these researchers conclude that the ECAE process can be carried out up to sixteen passages for the aforementioned aluminium alloy (AA-6061), which is in agreement with the results presented in the research developed by Tham et al. [7]. Another study is the one carried out by Luis Pérez and Luri [8] where they make a comparative analysis between finite element method (FEM) and both analytical and experimental results. The ECAE processed aluminium alloy in this research work is an AA-5083. These authors use analytical methods based on the upper bound method (UBM) so as to model and to compare the forces required in the ECAE process in the case of strain-hardening 


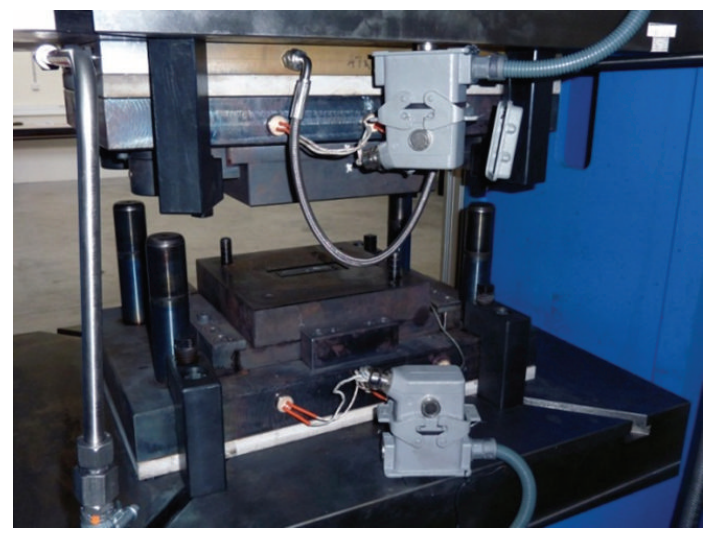

(a) Adapted system of heating/cooling

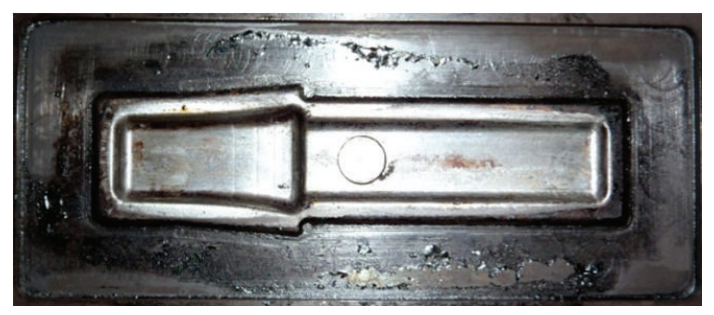

(b) Lower forging die of the straight blade

FIGURE 1: Forging dies.

materials. Furthermore, the buckling of the ECAE punch, which can appear in long parts, is studied by these authors.

As can be observed, the ECAE process has been mainly focused on aluminium alloy, whereas its application to other kinds of materials such as iron is more limited [9]. Luis et al. study the results achieved when Armco-Fe is ECAE processed up to four times at room temperature using route $C$ [9]. As has been shown in the above-mentioned technical papers and in the existing bibliography, one can find a large number of manuscripts about ECAE, but as far as we know, there are only a few among them that deal with starting material previously ECAE processed and then subsequently subjected to a plastic deformation process in order to manufacture a part [10-12].

In research work by Chaudhury et al. [10], the authors study the influence of the ECAE process over an AA-6061 subsequently hot forged. The ECAE processed billets of square cross section were obtained at room temperature and by using route $\mathrm{B}$. One of the most relevant conclusions is that it is possible to manufacture parts with lower values of forging temperature. Furthermore, the initial size of the billet to be forged is reduced as well as the size of flash obtained. Another significant research work is that by Lee et al. [11] in which the manufacturing of an impeller with twisted blades of microthickness is analysed, where this was made of the AZ31 magnesium alloy (with an initial grain size of $223 \mu \mathrm{m}$ ) and also ECAE processed. The grain refinement of the structure to be forged is carried out through four initial ECAE passages at a temperature of $400^{\circ} \mathrm{C}$ followed by five additional ECAE passages at $250^{\circ} \mathrm{C}$ with route $\mathrm{B}$. In this way, a complete filling of the forging dies is achieved because of the improvement in the flow of the material. Kim et al. [12] also carry out a study on the isothermal forgeability of the 6061 aluminium alloy after having been ECAE processed eight and twelve times with route $\mathrm{B}$. Again, one of the most relevant conclusions of this study is the decrease in the forging temperature along with an improvement in the surface quality of the forged parts.

In this present study, a straight blade, which can form a part of such important elements as compressors or fans, has been manufactured starting from AA-5083 previously processed by ECAE twice (N2) with route $\mathrm{C}$ at room temperature. Under these conditions, the material is ECAE processed approximately with an initial grain size of $0.5 \mu \mathrm{m}$ and an initial true strain between 2 and 2.4. The initial grain size of the material after being processed by ECAE also depends on subsequent heat treatments as is demonstrated in the studies from Huarte et al. and León et al. [13, 14]. Afterwards, the material will be used to be isothermally forged at different temperature values ranging from $25^{\circ} \mathrm{C}$ to $300^{\circ} \mathrm{C}$. Results regarding the improvement in the mechanical properties and in the microstructure obtained in the blade manufactured in this way are shown in relation to the nonultrafine grained (UFG) starting material. In addition, the optimum forging temperature for the isothermal forging of the blade will be determined. As shown in this research work, it is possible to obtain submicrometric grain size mechanical components with a higher mechanical strength value than that obtained in the non-UFG material.

\section{Experimentation Setup}

The isothermal forging was carried out on a hydraulic press of $3000 \mathrm{kN}$. Nevertheless, in order to carry out the experiments at different temperature values, it was necessary to modify the original equipment by adding a set of thermal resistances and thermocouples along with a cooling system, as can be observed in Figure 1(a).

Moreover, a supervisory control and data acquisition system (SCADA) was added to the press so as to achieve an accurate control of the heating of the forging dies. The design of the forging dies used here consists of two split dies; each of these has three distinguished parts (see Figure 1(b)): the back part with a constant cross section (where the preformed billet is supported), a transition zone where the cross section varies to shape the blade root, and the blade itself. The thickness of the blade is $5 \mathrm{~mm}$.

Forging tests were carried out using as starting material both annealed (N0) and ECAE processed (N2) AA-5083. For N0, the temperature values were room temperature and $150^{\circ} \mathrm{C}$. In the case of $\mathrm{N} 2$ as starting material, the forging temperature values were: $25^{\circ} \mathrm{C}, 100^{\circ} \mathrm{C}, 125^{\circ} \mathrm{C}, 150^{\circ} \mathrm{C}, 175^{\circ} \mathrm{C}$, $200^{\circ} \mathrm{C}, 250^{\circ} \mathrm{C}$, and $300^{\circ} \mathrm{C}$. 


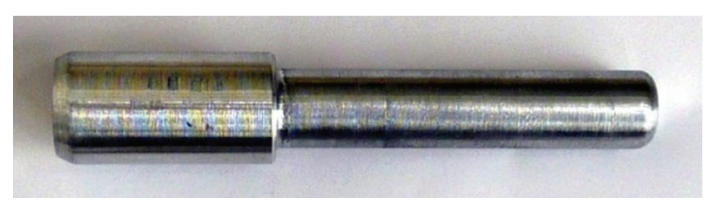

(a) Preformed billet of AA-5083

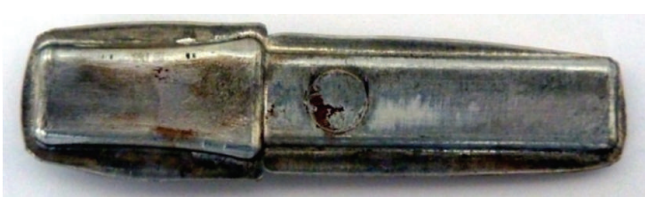

(b) Straight blade isothermally forged

FIGURE 2: Shape of the preformed billet and the manufactured straight blade.

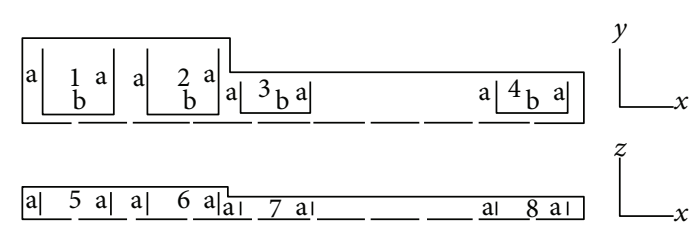

Figure 3: Blade zones (1 to 8) where the microhardness measurement (HV) was taken.

In all cases, the forging velocity was of $30 \mathrm{~mm} / \mathrm{min}$, and the maximum compression force was fixed at $1800 \mathrm{kN}$ because the hydraulic press control selected was by force instead of variable position.

The submicrometric grain size starting material to be forged was processed by ECAE twice using route $\mathrm{C}$ and a set of dies with a circular cross section with a diameter of $15 \mathrm{~mm}$ and equal fillet radii of $3 \mathrm{~mm}$. Subsequently, the ECAE billets were machined into the shape shown in Figure 2(a). The thus obtained preformance has two different cross sections: one with a diameter of $14 \mathrm{~mm}$, which corresponds to the blade root zone, and the other with a diameter of $10 \mathrm{~mm}$, which corresponds to the blade zone itself. Figure 2 (b) shows the straight blade forged at a specific temperature value after having been removed from the die with the help of ejector pins.

\section{Mechanical Properties Analysis}

Basically, the analysis of the mechanical properties obtained in the isothermally forged blades will be made through the microhardness measurement (Vickers Hardness, i.e., HV) at different zones of the blade shown in Figure 3. These zones were selected both in the longitudinal section $(x-y)$ and in the cross section $(x-z)$ of the blade. Zones 1 to 4 correspond to the blade longitudinal section, where 1 and 2 are located at the root and 3 and 4 at the blade itself. Zones 2 and 3 are the most interesting ones to be studied as the highest deformation values of the material are attained here. Zones 5 to 8 correspond to the blade cross section and are located at the same points as the longitudinal ones.

The number of microhardness measurements taken at each longitudinal zone was 9 , and in the case of transverse zones, this was 6 . Figure 4 shows the microhardness mean values at the different zones of the blade for all the forging tests.

The microhardness value for annealed AA-5083 is $\mathrm{HV}=$ 82.0, and after being processed by ECAE twice (route C), this value increases up to $\mathrm{HV}=135.7$. As can be observed in Figure 4, microhardness values in the blades forged with N2

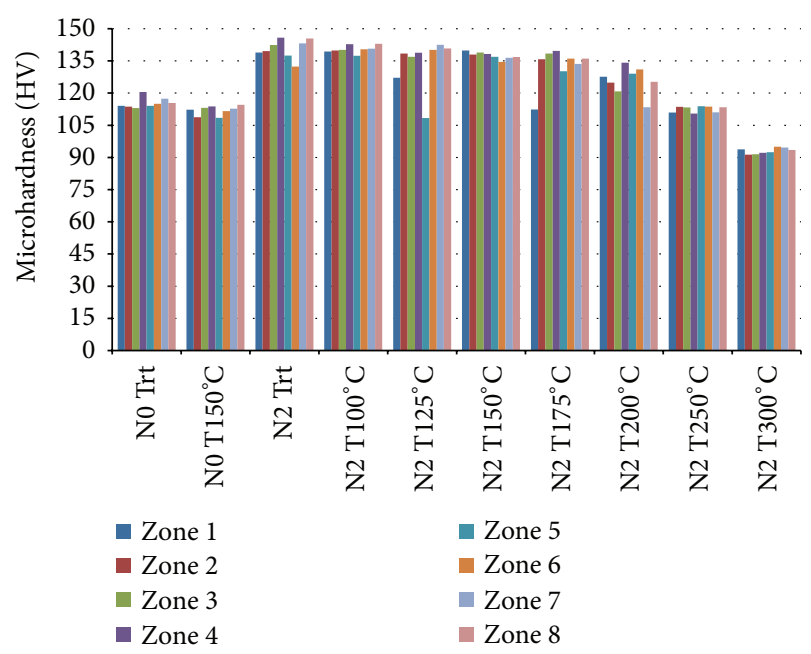

FIGURE 4: Microhardness values obtained at the defined zones of the AA-5083 straight blade for the isothermal forging tests carried out at different temperature values (where "rt" means room temperature, "N0" means the use of nonsubmicrometric grain size AA-5083 as starting material, and "N2" means the use of AA5083 submicrometric structure obtained by ECAE twice as starting material).

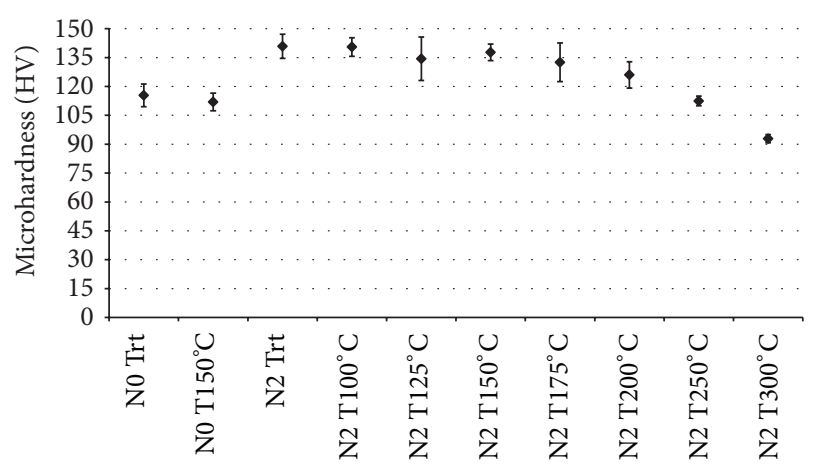

FIGURE 5: Microhardness values for the different forged blades.

as starting material and at temperature values lower than that of recrystallization $\left(100^{\circ} \mathrm{C}\right.$ to $\left.200^{\circ} \mathrm{C}\right)$ are higher than those obtained in the blades forged with N0 as starting material. The forgeability improves with forging temperature which is supported by the fact that no internal cracks appear in the blades with $\mathrm{N} 2$ as starting material at a temperature of $175^{\circ} \mathrm{C}$. Therefore, this forging temperature of $175^{\circ} \mathrm{C}$ is considered to be the optimum in the case of this aluminium alloy. 


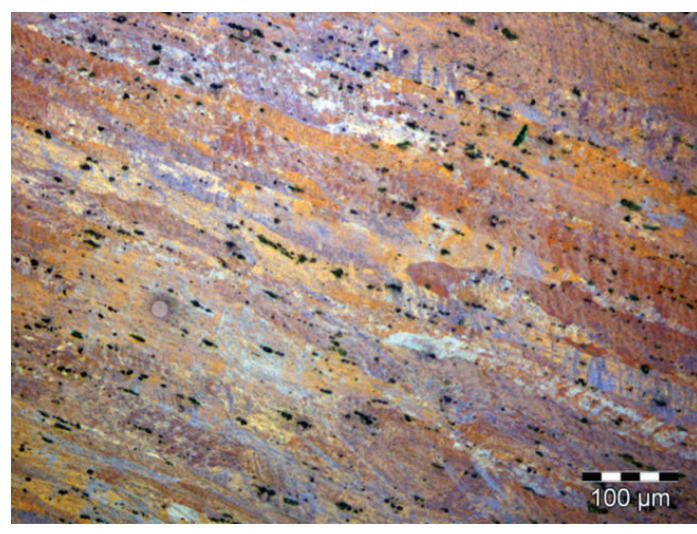

(a) N2 as starting material and forged at $100^{\circ} \mathrm{C}$

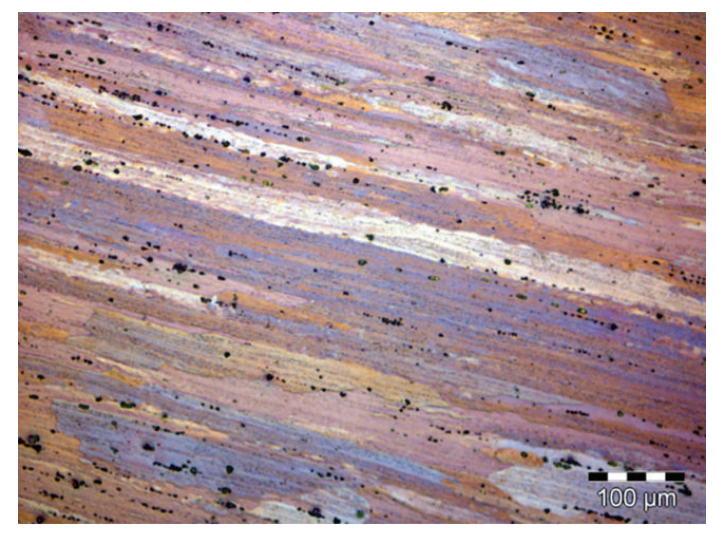

(b) N0 as starting material and forged at $25^{\circ} \mathrm{C}$

Figure 6: Optical micrographs at 200x of zone 6 of the blades.

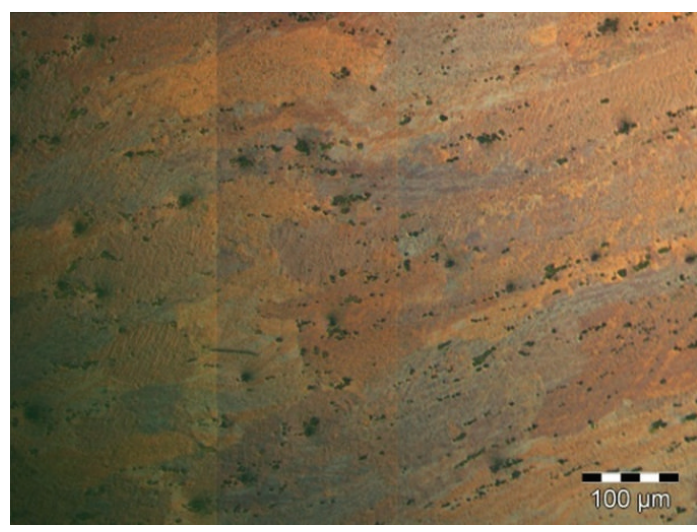

(a) Forged at $200^{\circ} \mathrm{C}$

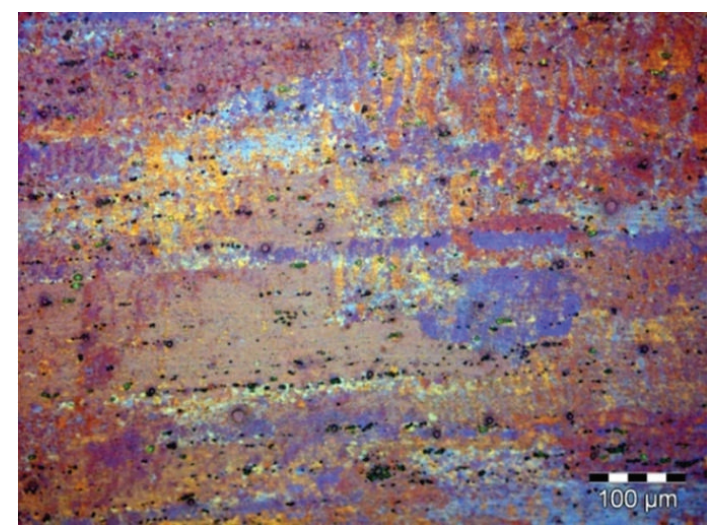

(b) Forged at $300^{\circ} \mathrm{C}$

FIgURE 7: Optical micrograph at 200x of zone 2 of the blade with N2 as starting material.

Moreover, Figure 5 shows the microhardness mean value for each forged blade and their corresponding standard deviation values. It may be stated from Figure 5 that there seems to be a tendency for the microhardness variability to decrease as the forging temperature is increased. This may be due to the decrease in the grain size and its homogeneity throughout the blade.

\section{SEM and Optical Analysis}

Microstructure of isothermally forged AA-5083 blades was analysed by both optical and scanning electron microscopy (SEM).

4.1. Optical Microscopy. For the optical microscopy analysis, the blade samples were polished and subsequently etched with Barker's reagent. Micrographs were taken at the same zones of the billet where microhardness measurements were taken in order to observe the internal microstructure.

The blades forged at temperature values lower than recrystallization present a microstructure where the grains are distorted due to the strain accumulated by ECAE and the forging process.
Figure 6(a) shows an optical micrograph of the N2 blade forged at $100^{\circ} \mathrm{C}$. In Figure 6(b), the microstructure of the N0 blade forged at $25^{\circ} \mathrm{C}$ is shown. Deformation bands can be observed more clearly than that shown in Figure 6(a). This occurs because the forge was made very far below the recrystallization temperature.

As the recrystallization is being reached, the deformation bands disappear, and the new grains start to grow around them, as can be observed in Figure 7(a). However, if the forging temperature is increased up to recrystallization, the microstructure presents a new grain structure. Figure 7(b) shows an optical micrograph of the N2 blade forged at $300^{\circ} \mathrm{C}$ where most of its microstructure is recrystallized.

4.2. SEM Analysis. Scanning electron microscopy (SEM) was used. Samples were electropolished with perchloric acid, ethanol, and glycerine. All the SEM micrographs were obtained using backscattered electrons.

Figure 8(a) shows a SEM micrograph from N0 forged blade at $25^{\circ} \mathrm{C}$. It can be observed that the grain size is close to $1 \mu \mathrm{m}$. In Figure 8(b), $\mathrm{N} 2$ blade forged at $25^{\circ} \mathrm{C}$ can be observed. Comparing Figure 8(a) with Figure 8(b), it is shown that 


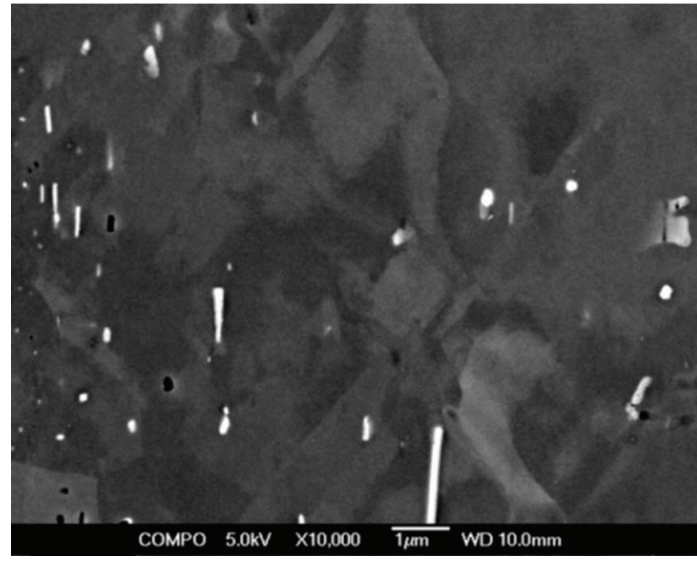

(a) Zone 1 with $\mathrm{N} 0$ as starting material

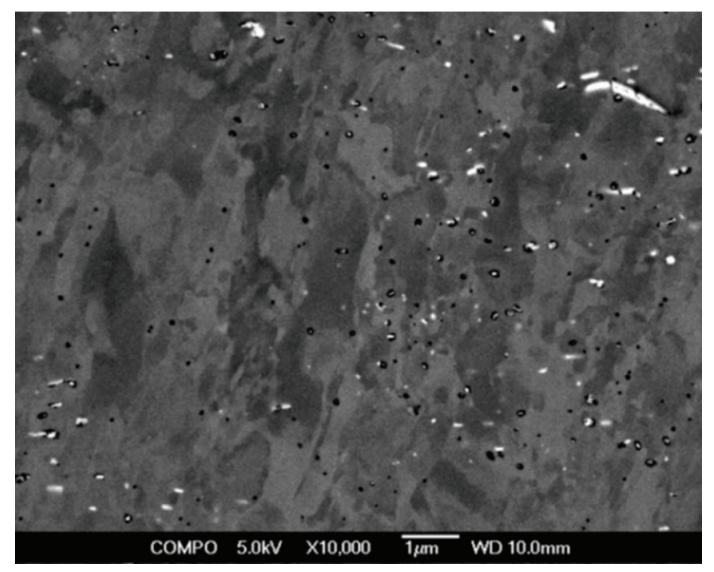

(b) Zone 2 with $\mathrm{N} 2$ as starting material

Figure 8: SEM micrographs at $10000 \mathrm{x}$ of the blades forged at $25^{\circ} \mathrm{C}$.

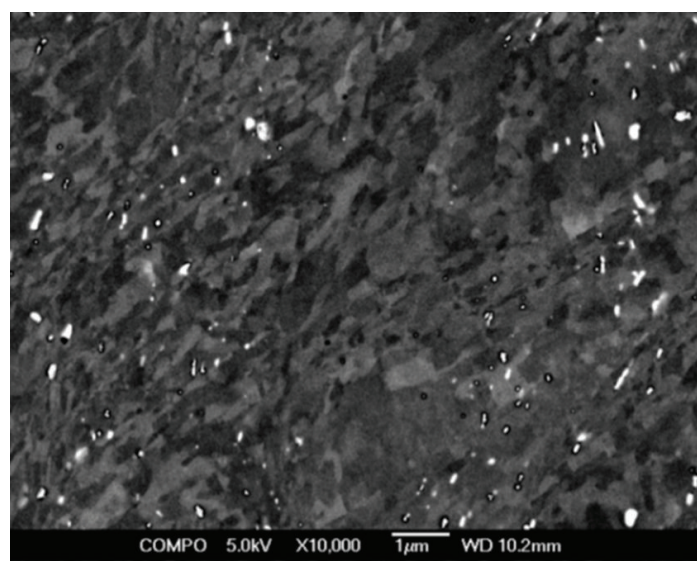

(a) Forged at $100^{\circ} \mathrm{C}$

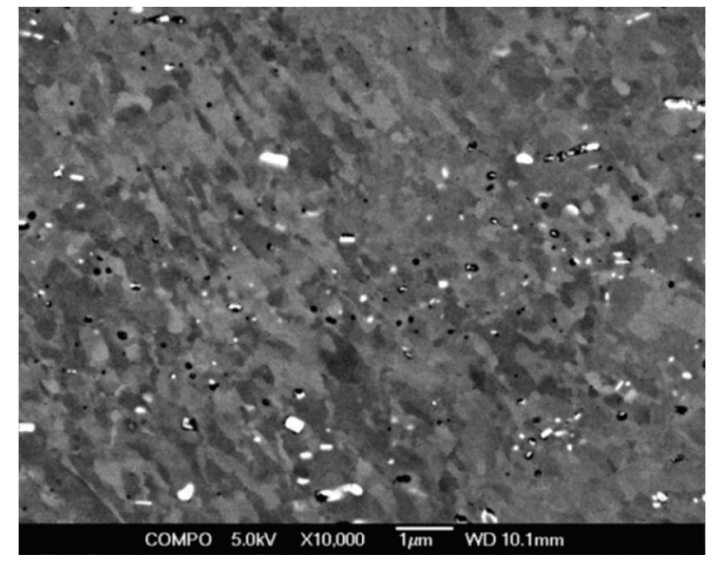

(b) Forged at $175^{\circ} \mathrm{C}$

FIgURE 9: SEM micrographs at 10000x of zone 2 of the blades with N2 as starting material.

grains have more distortion in the $\mathrm{N} 2$ forged blade, due to the strain accumulation during the ECAE process.

However, once the material has been forged at a temperature value above $25^{\circ} \mathrm{C}$, a more homogeneous grain distribution is observed in the internal microstructure (Figure 9(a)). Also, the presence of new grains indicates that recrystallization has started. In this case, the forging temperature is $100^{\circ} \mathrm{C}$. Recrystallization is more evident at temperatures above $100^{\circ} \mathrm{C}$ as shown in Figure 9(b). At 10000x, a high number of new grains can be observed. This internal microstructure corresponds with $\mathrm{N} 2$ forged blade at $175^{\circ} \mathrm{C}$, which is the optimum temperature for this process.

Up to a temperature value of $200^{\circ} \mathrm{C}$, the microstructure is in a recovery state. This can be observed in Figure 10(a), and a submicrometric microstructure is revealed as well. Figure 10(b) shows the grain size at 25000x where a complete recrystallization of the material is revealed. A homogeneous grain distribution can be appreciated.

As shown in Figures 11(a) and 11(b), the grain size has increased in comparison with the submicrostructure obtained in Figure 10(b), due to the increase in the forging temperature. In Figure 11 (a) the forging value is $250^{\circ} \mathrm{C}$, so the grain growth begins to be appreciated. Figure 11(b) shows the microstructure of the blade forged at $300^{\circ} \mathrm{C}$, where the grain size continues growing.

\section{Conclusions}

In this study, a straight blade was manufactured from AA5083 previously processed by ECAE twice with route C. Afterwards, this material was isothermally forged at different temperature values ranging from $25^{\circ} \mathrm{C}$ to $300^{\circ} \mathrm{C}$.

The temperature of $175^{\circ} \mathrm{C}$ is considered to be the optimum forging temperature in the case of this aluminium alloy since no internal cracks appear in the blade and there is only a very slight decrease in its microhardness compared to that of the submicrometric grain size starting material. Moreover, the microhardness of the forged blade at this recovery temperature of $175^{\circ} \mathrm{C}$ is higher than those obtained with $\mathrm{N} 0$ as starting material. 


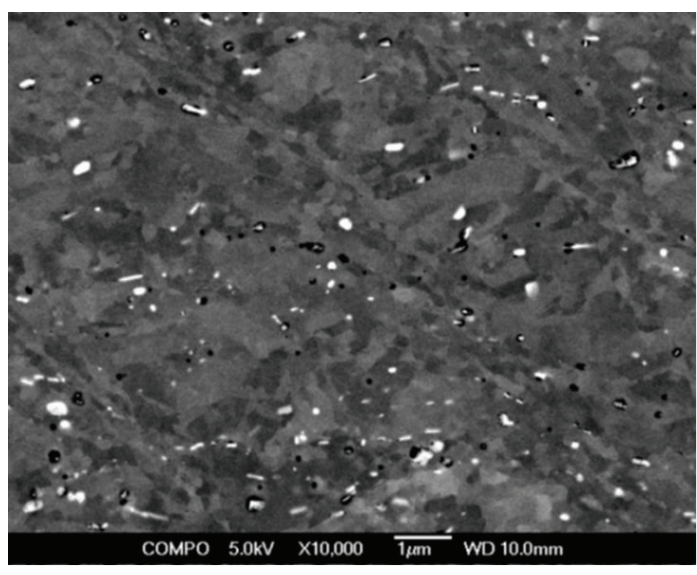

(a) 10000x of zone 2

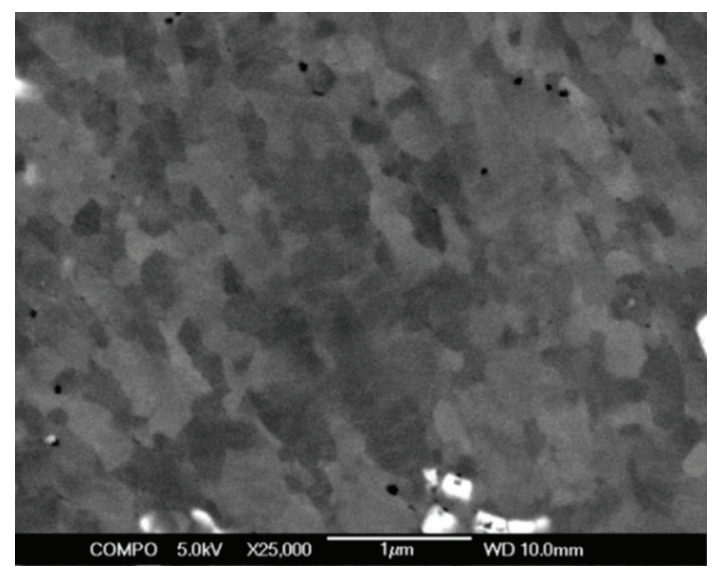

(b) 25000x of zone 5

FIGURE 10: SEM micrographs of the blade with N2 as starting material and forged at $200^{\circ} \mathrm{C}$.

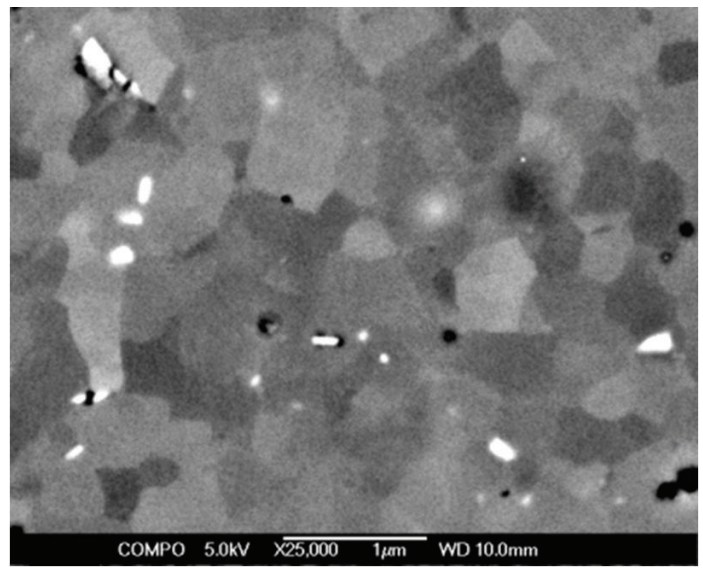

(a) $25000 \mathrm{x}$ and forged at $250^{\circ} \mathrm{C}$

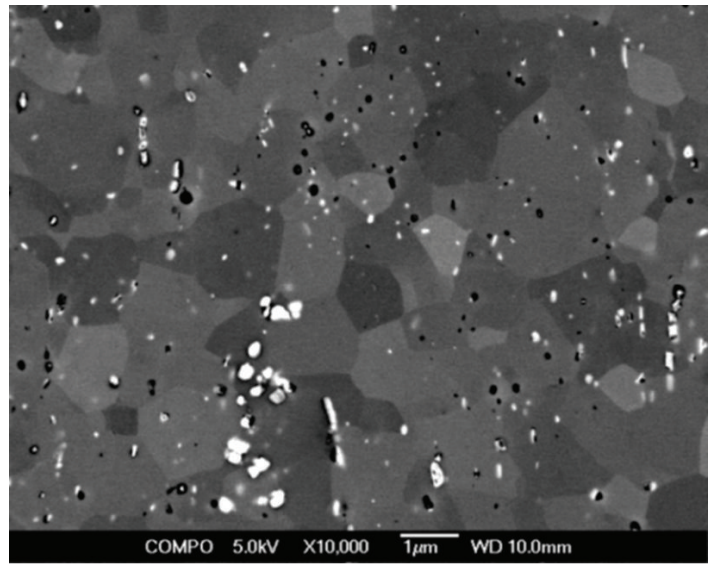

(b) $10000 \mathrm{x}$ and forged at $300^{\circ} \mathrm{C}$

FIGURE 11: SEM micrographs at 10000x of zone 2 of the blade with N2 as starting material.

In appropriate processing conditions, it is possible to obtain submicrometric structure in the isothermally forged parts obtained from previously ECAE processed materials. Therefore, with this present study, we have demonstrated that it is possible to obtain straight blades with improved mechanical properties compared to those obtained with conventional methods.

\section{Acknowledgment}

The authors acknowledge the support given by the Spanish former Ministry of Science and Innovation (now Ministry of Economy and Competitiveness) under the Research Project DPI2010-18941.

\section{References}

[1] G. Faraji and H. Jafarzadeh, "Accumulative torsion back (ATB) processing as a new plastic deformation technique," Materials and Manufacturing Processes, vol. 27, no. 5, pp. 507-511, 2012.
[2] B. Cherukuri and R. Srinivasan, "Properties of AA6061 processed by multi-axial compressions/forging (MAC/F)," Materials and Manufacturing Processes, vol. 21, no. 5, pp. 519-525, 2006.

[3] M. Raei, M. R. Toroghinejad, and R. Jamaati, "Nano/ultrafine structured AA1100 by ARB process," Materials and Manufacturing Processes, vol. 26, no. 11, pp. 1352-1356, 2011.

[4] V. M. Segal, "Engineering and commercialization of equal channel angular extrusion (ECAE)," Materials Science and Engineering A, vol. 386, no. 1-2, pp. 269-276, 2004.

[5] C. J. Luis Pérez and R. Luri, "Study of the ECAE process by the upper bound method considering the correct die design," Mechanics of Materials, vol. 40, no. 8, pp. 617-628, 2008.

[6] M. W. Fu, M. S. Yong, Q. X. Pei, and H. H. Hng, "Deformation behavior study of multi-pass ECAE process for fabrication of ultrafine or nanostructured bulk materials," Materials and Manufacturing Processes, vol. 21, no. 5, pp. 507-512, 2006.

[7] Y. W. Tham, M. W. Fu, H. H. Hng, Q. X. Pei, and K. B. Lim, "Microstructure and properties of Al-6061 alloy by equal channel angular extrusion for 16 passes," Materials and Manufacturing Processes, vol. 22, no. 7-8, pp. 819-824, 2007. 
[8] C. J. Luis Pérez and R. Luri, "Comparative analysis of actual processing conditions in ECAE between FEM and both analytical and experimental results," Materials and Manufacturing Processes, vol. 26, no. 9, pp. 1147-1156, 2011.

[9] C. J. Luis, I. Puertas, R. Luri, J. León, D. Salcedo, and I. Pérez, "Development of nanostructured Armco-Fe by equal channel angular extrusion (ECAE)," Materials and Manufacturing Processes, vol. 27, no. 12, pp. 1276-1284, 2012.

[10] P. K. Chaudhury, B. Cherukuri, and R. Srinivasan, "Scaling up of equal-channel angular pressing and its effect on mechanical properties, microstructure, and hot workability of AA 6061," Materials Science and Engineering A, vol. 410-411, pp. 316-318, 2005.

[11] J. H. Lee, S. H. Kang, and D. Y. Yang, "Novel forging technology of a magnesium alloy impeller with twisted blades of microthickness," CIRP Annals-Manufacturing Technology, vol. 57, no. 1, pp. 261-264, 2008.

[12] W. J. Kim, Y. K. Sa, H. K. Kim, and U. S. Yoon, "Plastic forming of the equal-channel angular pressing processed 6061 aluminum alloy," Materials Science and Engineering A, vol. 487, no. 1-2, pp. 360-368, 2008.

[13] B. Huarte, C. J. Luis, R. Luri, and R. León, "A study on the heat treatments of deformed AA5083 by the ECAE process," International Journal of Computational Materials Science and Surface Engineering, vol. 2, no. 1-2, pp. 128-136, 2009.

[14] J. León, C. J. Luis, R. Luri, B. Huarte, and I. Puertas, "Comparative study of the required force for performing equal channel angular extrusion with routes A and C," Current Nanoscience, vol. 3, no. 3, pp. 241-244, 2007. 

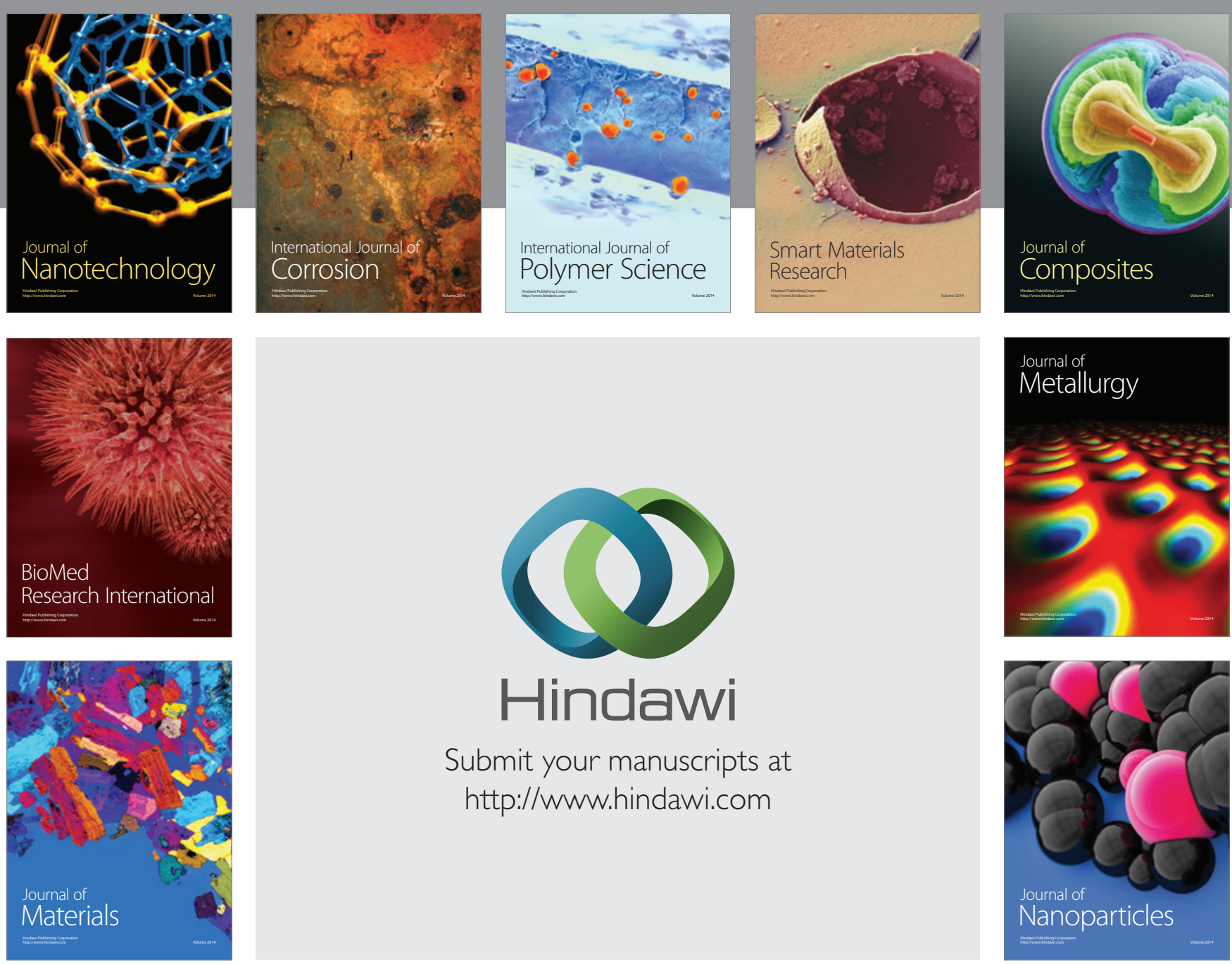

Submit your manuscripts at http://www.hindawi.com
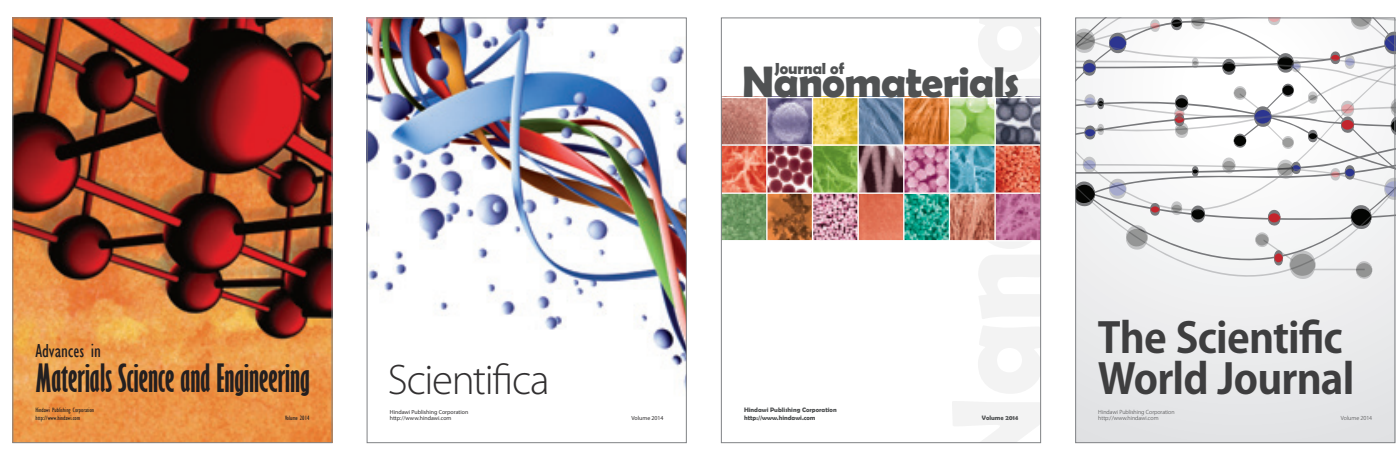

\section{The Scientific World Journal}
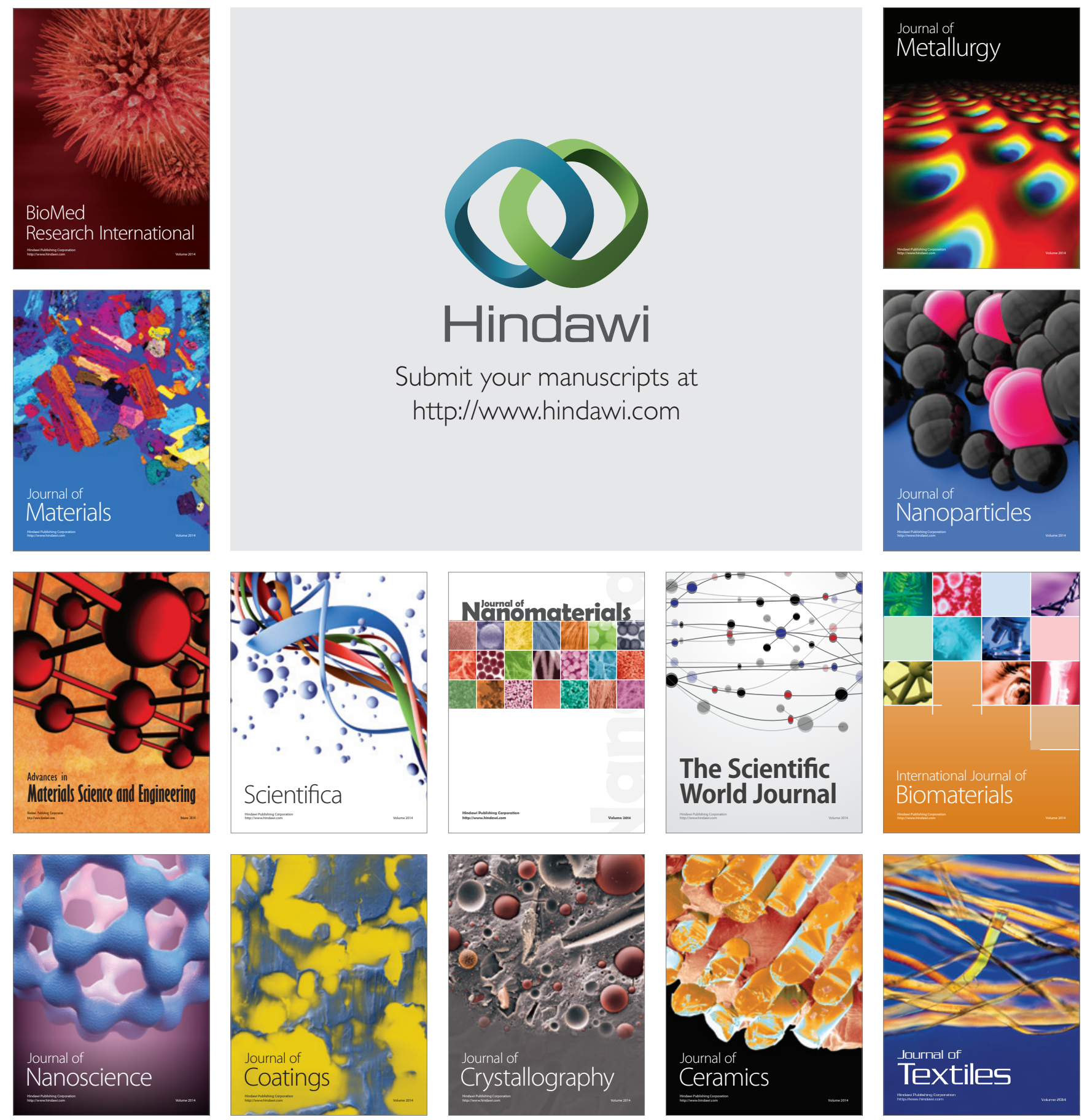